\title{
Complete interruption of aortic arch, without persistent ductus arteriosus, in an adult
}

\author{
Geoffrey P. Sharratt, Peter Carson, and James M. Sanderson \\ From the North Staffs Hospital Group, Stoke-on-Trent
}

A case of complete interruption of the aortic arch in an adult is presented and the previous 8 reported cases are reviewed. Obliteration of the ductus arteriosus is a feature of these cases, in contrast to the more common variety found in early childhood. Comments are made on the clinical distinction between the adult type of complete interruption of the aortic arch and coarctation of the aorta.

Complete interruption of the aortic arch is a rare congenital anomaly, sometimes referred to as Steidele's complex or CIAA. The diagnosis is usually made at necropsy in infancy, and in these cases there has invariably been persistence of the ductus arteriosus and almost invariably a ventricular septal defect (Roberts, Morrow, and Braunwald, 1962). Survival to adult life is rare, and to our knowledge only 8 cases have been previously reported in the English language. We now describe a further case and comment upon the diagnosis, surgical management, and the difference between the adult and the infantile cases.

\section{Case report}

The patient was a I5-year-old Caucasian youth. His birthweight was $3317 \mathrm{~g}$ and the neonatal period and subsequent development were uneventful in that he was walking at 14 months and speech was well co-ordinated at 3 years. At the age of 2 years 8 months he was seen because of a persistent cough and the chest $x$-ray was said to show a slight suggestion of rib notching. The femoral arteries were thought to be palpable at that time but the child was irritable and difficult to examine. No follow-up was arranged. The following year a right inguinal hernia was repaired and no other abnormality was noted at that time. At the age of ro years he was seen because of an undescended testis and again no other abnormality was noted.

He remained well until July 1973 when he was seen because of neurological symptoms. For 12 months he had been having frontal headaches, usually right-sided. Twelve days before admission he had awoken with a right temporal headache and had then developed clumsiness of the right arm with paraesthesiae in the right hand, some expressive dysphasia, and blurring of vision of the right eye. This lasted for 2 hours, then cleared completely. One day later he had a further episode of transient blurring of vision in the right eye which lasted a few minutes.

His father died of a subarachnoid haemorrhage but no necropsy was performed. His paternal grandfather has had a cerebrovascular accident, and he is hypertensive but the peripheral pulses are all normal.

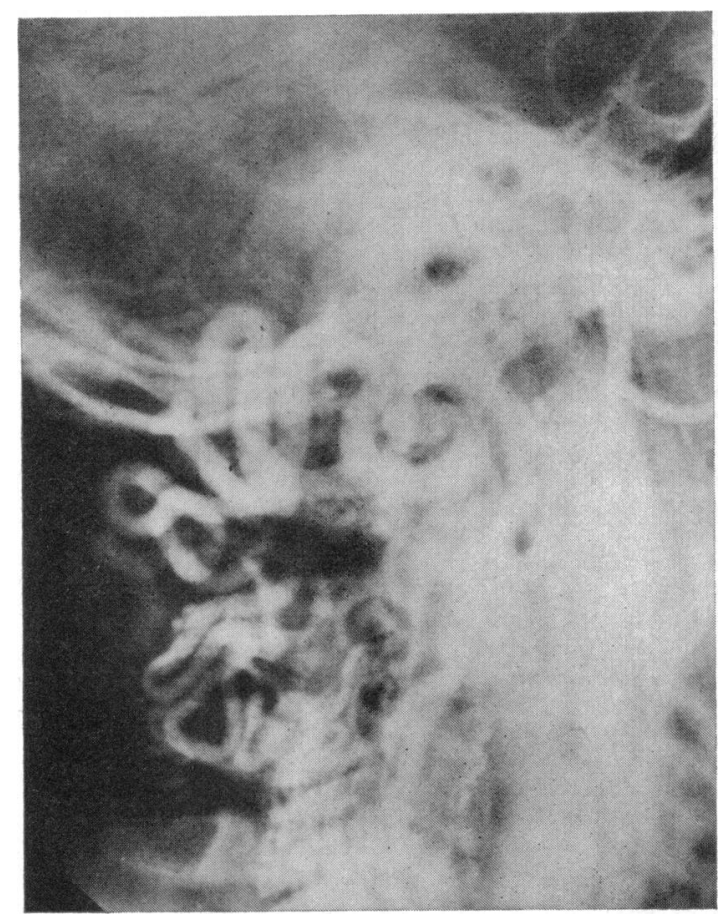

FIG. I Lateral view of the left carotid arteriogram showing large tortuous arteries in the occipital region. 
On examination he was obese, with a weight above the 9oth percentile for age, and his height was at the 5oth centile. No pulses were palpable in the left arm or either leg. The carotids were bounding and the blood pressure was $220 / 90 \mathrm{mmHg}$ in the right arm. There was an increased left ventricular impulse displaced to the anterior axillary line, and there was no right ventricular lift. On auscultation the first and second heart sounds were normal, there was a grade $3 / 6$ ejection systolic murmur at the left sternal edge and maximal below the left clavicle. There was a soft early diastolic murmur at the left sternal edge. Palpable collateral pulsation was found medial to the right scapula and behind the sternomastoid muscles bilaterally with a systolic bruit on the right side of the occipital region. The retinal arteries were tortuous.

The electrocardiogram showed sinus rhythm and pronounced left ventricular hypertrophy with $T$ wave inversion in leads $V_{5}$ and V6. The chest $x$-ray showed absence of the aortic knuckle and pronounced rib notching, but only on the right side.

Carotid arteriograms were performed. On the left side no intracranial filling was obtained but there was filling of large tortuous arteries in the posterior part of the neck (Fig. I). It was thought that the needle was in one of these abnormal vessels and not in the left carotid artery. On the right side the intracranial vessels appeared normal but there was filling of the basilar system and abnormal vessels in the neck. Vascular spasm occurred and the patient became confused but by the next day was back to normal.

Left heart catheterization was performed from the right brachial artery. There was no gradient across the aortic valve and the pressure in the ascending aorta was $210 / 120 \mathrm{mmHg}$. An aortogram was performed with the patient in a steep left anterior oblique position. The contrast medium was seen to outline the right subclavian and right and left common carotid arteries but no descending aorta was seen, the arch ending after giving off the left common carotid. Later films showed outlining of the descending aorta and left subclavian artery by retrograde flow from the left vertebral artery. The right internal mammary artery was enormously dilated and many small collateral vessels were seen in the chest and neck (Fig. 2).

The diagnosis was therefore considered to be complete interruption of the aortic arch between the left common carotid artery and the left subclavian artery.

This diagnosis was confirmed at operation. A good exposure of the whole field was obtained by a median sternotomy incision with extension into the third left intercostal space. The exposure was greatly assisted by deflation of the left lung using a Carlens' cuffed endotracheal tube. Control of bleeding from the collateral vessels present was helped by the use of hypotension. Cardiopulmonary bypass was not necessary. There was

TABLE Salient features of 9 cases of 'adult' complete interruption of aortic arch

\begin{tabular}{|c|c|c|c|c|}
\hline No. & Reference & $\begin{array}{l}\text { Age } \\
(y r)\end{array}$ & Symptoms & Rib notching \\
\hline I & Villalobos et al. (196I) & 14 & $\begin{array}{l}\text { Headache, fainting, dyspnoea, } \\
\text { epistaxis }\end{array}$ & Bilateral \\
\hline 2 & Pillsbury, Lower, and Shumway (1964) & 16 & Dyspnoea, sore legs on walking & Right side \\
\hline 3 & Zetterqvist (1967) & 8 & Nil & Nil \\
\hline 4 & Morgan et al. (1970) & 19 & Nil & Nil \\
\hline 5 & Chiemmongkoltip, Moulder, and Cassels (197r) & 16 & Dyspnoea, cyanosis & Nil \\
\hline 6 & Takashina et al. (1972) & 32 & Dyspnoea, ankle oedema & Nil \\
\hline 7 & Kauff, Bloch, and Baltaxe (1973) & 36 & Renal colic & Bilateral \\
\hline 8 & Kauff et al. (1973) & 49 & $\begin{array}{l}\text { Visual disturbance, dysphasia, } \\
\text { memory loss }\end{array}$ & Bilateral \\
\hline 9 & Present case & 15 & $\begin{array}{l}\text { Headache, visual disturbance, } \\
\text { dysphasia }\end{array}$ & Right side \\
\hline
\end{tabular}


a $5 \mathrm{~cm}$ gap between the termination of the aortic arch and the beginning of the descending aorta. A ligamentum arteriosum was present connecting the descending aorta with the left pulmonary artery. The ligamentum arteriosum was divided and a $2 \mathrm{~cm}$ diameter 'dacron' tube, ro $\mathrm{cm}$ long, was inserted between the ascending and descending aorta.

Immediately after operation good pulses were palpable in the left arm and the legs, and no hypertensive episodes occurred. Recovery was uneventful. Three months after the operation the pulses were still palpable in the left arm and both legs, but no collateral vessels were now palpable and no bruit was heard in the occipital area. The blood pressure in the right arm was $180 / 85 \mathrm{mmHg}$. No early diastolic murmur was heard.

\section{Discussion}

Complete interruption of the aortic arch is a rare congenital abnormality. Most patients die in infancy, and a few have survived into early childhood. There have been 8 previously reported cases of complete interruption of the aortic arch with survival into later childhood or adult life. The salient features of these 8 cases and the case here reported are shown in the Table. In the cases found in infancy and early childhood there is invariably persistence of the ductus arteriosus and almost

\begin{tabular}{|c|c|c|}
\hline Site & $\begin{array}{l}\text { Other } \\
\text { anomalies }\end{array}$ & Surgery \\
\hline $\begin{array}{l}\text { Left subclavian } \\
\text { to descending } \\
\text { aorta }\end{array}$ & $\begin{array}{l}\text { Persistent ductus } \\
\text { arteriosus }\end{array}$ & Dacron graft \\
\hline $\begin{array}{l}\text { Right common } \\
\text { carotid to left } \\
\text { common carotid }\end{array}$ & Nil & Dacron graft \\
\hline $\begin{array}{l}\text { Left common } \\
\text { carotid to left } \\
\text { subclavian }\end{array}$ & $\begin{array}{l}\text { Aberrant right } \\
\text { subclavian artery }\end{array}$ & $\begin{array}{l}\text { Side-to-end } \\
\text { anastomosis }\end{array}$ \\
\hline $\begin{array}{l}\text { Left common } \\
\text { carotid to left } \\
\text { subclavian }\end{array}$ & $\begin{array}{l}\text { Aberrant right } \\
\text { subclavian } \\
\text { artery }\end{array}$ & Dacron graft \\
\hline $\begin{array}{l}\text { Left subclavian } \\
\text { to descending } \\
\text { aorta }\end{array}$ & $\begin{array}{l}\text { Aortico- } \\
\text { pulmonary } \\
\text { window }\end{array}$ & $\begin{array}{l}\text { Banding of } \\
\text { pulmonary } \\
\text { artery }\end{array}$ \\
\hline Unknown & $\begin{array}{l}\text { Ventricular } \\
\text { septal defect; } \\
\text { persistent ductus } \\
\text { arteriosus }\end{array}$ & Nil \\
\hline $\begin{array}{l}\text { Left common } \\
\text { carotid to left } \\
\text { subclavian }\end{array}$ & $\begin{array}{l}\text { Bicuspid aortic } \\
\text { valve }\end{array}$ & $\begin{array}{l}\text { End-to-end } \\
\text { anastomosis }\end{array}$ \\
\hline $\begin{array}{l}\text { Left subclavian } \\
\text { to descending } \\
\text { aorta }\end{array}$ & $\begin{array}{l}\text { Aberrant right } \\
\text { subclavian } \\
\text { artery }\end{array}$ & Dacron graft \\
\hline $\begin{array}{l}\text { Left common } \\
\text { carotid to left } \\
\text { subclavian }\end{array}$ & Nil & Dacron graft \\
\hline
\end{tabular}

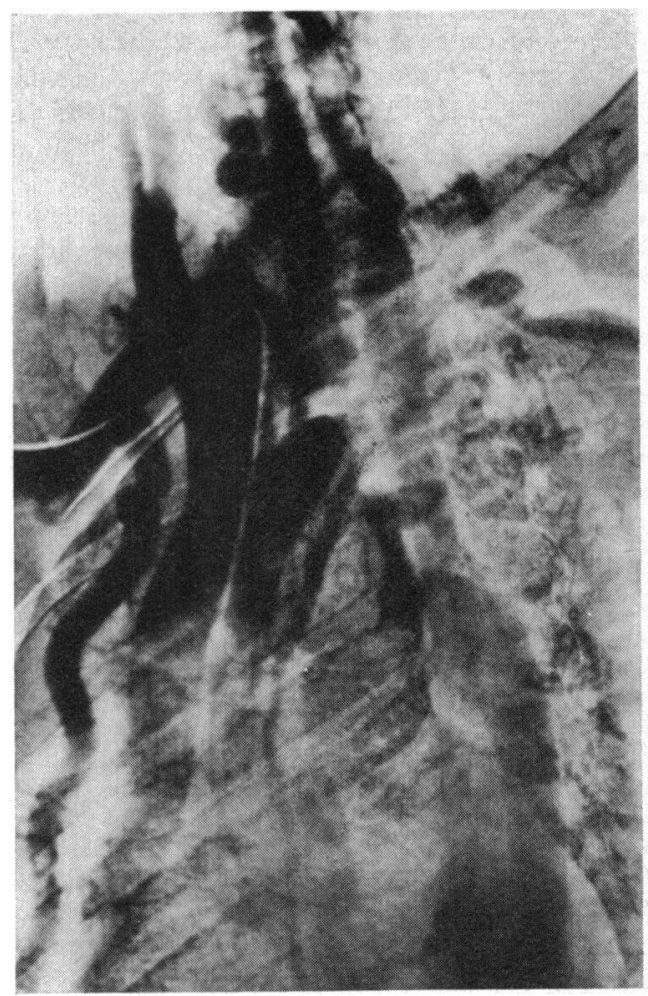

( $A$ )

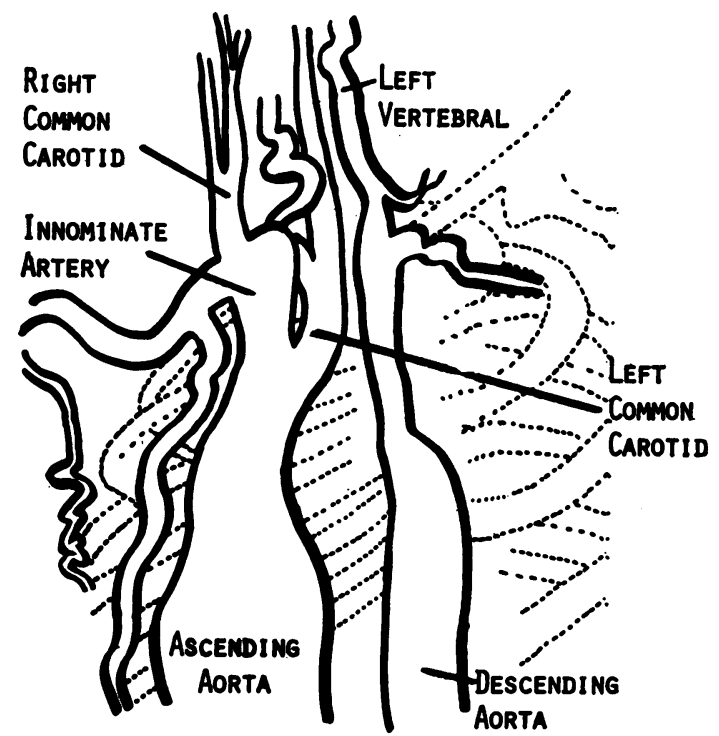

(B)

FIG. $2 A$ ) Subtraction film of the arch aortogram, left anterior oblique projection, 8 seconds after injection of the contrast medium into the ascending aorta. $B$ ) Diagrammatic representation of Fig. $2 A$. 
invariably a ventricular septal defect. Of the 9 cases surviving beyond early childhood, only 2 (Cases I and 6) had a persistent ductus arteriosus. Case 6 had neither an aortogram nor operation performed so cannot be considered to be a definite example of a completely interrupted aortic arch. In Case I a ductus was definitely present and the pressure in the pulmonary artery was $90 / 36 \mathrm{mmHg}$. In all the other cases surviving beyond early childhood, a persistent ductus was not present and a collateral circulation supplying the descending aorta had developed. Considering the severity of the lesion, these patients are remarkably free of symptoms. In our case, Cases I and 8, the predominant symptoms related to the central nervous system. In Case 8 these symptoms were thought to be caused by hypertensive encephalopathy, but in our case a more likely explanation was 'vertebral steal' since retrograde flow down the left vertebral artery to the descending aorta was demonstrated and carotid arteriograms showed filling of the vertebrobasilar system from an injection of the right carotid artery.

Operation in this case was carried out through a median sternotomy extended into the third left intercostal space. This incision, combined with deflation of the left lung, using a Carlens' cuffed endotracheal tube, permitted excellent exposure of the operative field. Bleeding from the extensive collateral vessels was a problem but this was greatly minimized by the use of hypotension.

Collateral flow to the descending aorta follows several routes. As with coarctation of the aorta, the posterior intercostal arteries act as collateral flow to the descending aorta. However, in our case the origin of the left internal mammary artery was beyond the interruption of the aortic arch and so this vessel could not act as a collateral to the descending aorta via the posterior intercostal arteries. This explains why the rib notching was limited to the right side of the chest. This feature was also present in Case 2. An aberrant right subclavian artery was present in Cases 3, 4, and 8, and in these cases acted as an important collateral vessel. Abnormal vessels in the neck were noted in Cases 2, 3, 4, and 9, and retrograde flow in the vertebral arteries was noted in Cases 3, 4, and 9.

This pattern of collateral circulation offers itself as an important differentiating feature between complete interruption of the aortic arch and coarctation of the aorta. If, in a case of supposed coarctation of the aorta, abnormal vessels are palpated in the neck, if there are bruits in the neck, or unilateral rib notching is present, complete interrup- tion of the aortic arch is suggested. In our case, another feature that was thought to be unusual for coarctation was the electrocardiogram which showed gross left ventricular hypertrophy with $T$ wave changes.

We thank Dr. Walter van't Hoff for referring this case, Dr. Alan Hugh for radiological help, Dr. Gytis Danta for neurological help, Dr. Jutta O'Meara for much help in preparation of the paper, and Mr. Jim Lawson for advice about the surgical management.

\section{Addendum}

Since this report was prepared there has been one further case reported (Judez et al., 1974). In this case the interruption was between the left common carotid artery and the left subclavian artery, with the origin of the right subclavian artery being aberrant. No definite rib notching was noted, but, as in our case, there were prominent abnormal vessels in the neck, with filling of the descending aorta by retrograde flow in the vertebral arteries.

\section{References}

Chiemmongkoltip, P., Moulder, P. V., and Cassels, D. E. (197I). Interruption of the aortic arch with aortico-pulmonary septal defect and intact ventricular septum in a teenage girl. Chest, 60, 324 .

Judez, V. M., Maitre, M. J., de Artaza, M., de Miguel, J. M. F., Valles, F., and Marquez, J. (1974). Interruption of aortic arch without associated cardiac abnormalities. British Heart Fournal, 36, 313.

Kauff, M. K., Bloch, J., and Baltaxe, H. A. (1973). Complete interruption of the aortic arch in adults. Radiology, 106, 53.

Morgan, J. R., Forker, A. D., Fosburg, R. G., Neugebauer, M. K., Rogers, A. K., and Bemiller, C. R. (1970). Interruption of the aortic arch without a patent ductus arteriosus. Circulation, 42, 961 .

Pillsbury, R. C., Lower, R. R., and Shumway, N. E. (I964). Atresia of the aortic arch. Circulation, 30, 749.

Roberts, W. C., Morrow, A. G., and Braunwald, E. (I962). Complete interruption of the aortic arch. Circulation, 26, 39.

Takashina, T., Ishikura, Y., Yamane, K., Yorifuji, S., Iwasaki, T., Yoshida, Y., Takeshita, I., and Oka, K. (1972). The congenital cardiovascular anomalies of the interruption of the aorta - Steidele's complex. American Heart fournal, 83, 93.

Villalobos, M. C. R., De Balderrama, D. P., Lopez, J., and Castellanos, M. (I96I). Complete interruption of the aorta. American fournal of Cardiology, 8, 664 .

Zetterqvist, P. (1967). Atypical coarctation of the aorta with bilateral vertebral-subclavian pathway. Scandinavian Fournal of Thoracic and Cardiovascular Surgery, $1,68$.

Requests for reprints to Dr. Peter Carson, Cardiac Department, City General Hospital, Newcastle Road, Stoke-on-Trent ST 46 QG, Staffs. 